\section{How miniRUEDI sniffs the world: towards real time on-site analysis of (noble) gases in the context of fracking and nuclear waste disposal}

\author{
ROLF KIPFER ${ }^{1}$, MATTHIAS BRENNWALD ${ }^{2}$ AND DR. \\ YAMA TOMONAGA ${ }^{3}$ \\ ${ }^{1}$ Eawag \\ ${ }^{2}$ Swiss Federal Institute of Aquatic Science and Technology \\ (Eawag) \\ ${ }^{3}$ Eawag, Swiss Federal Institute of Aquatic Science and \\ Technology \\ Presenting Author: rolf.kipfer@eawag.ch
}

Atmospheric noble gases enter aquatic systems by gas/water partitioning. Consequently, aquatic noble gas concentrations in waters reflect the physical conditions prevailing during gas exchange. Dissolved atmospheric noble gases are thus powerful tracers to understand and to quantify gas / water partitioning, and allow reconstructing past environmental / climatic conditions. These concepts have e.g., been used to analyse groundwater recharge in Northern America during the last glaciation [1].

However, conventional laboratory techniques for determining (noble) gases in terrestrial fluids and water are laborious, expensive and only allow limited number of samples to be analyzed.

To side-step these technical limitations, new methods were developed to quantify (noble) gas concentrations in terrestrial fluids under field conditions [2,3]. Our new, self-contained and portable mass spectrometer miniRUEDI $[1,4]$ can be operated in the field $(32 \mathrm{~kg}, 50 \mathrm{~W})$ and allows the quasi-continuous quantification of $\mathrm{He}, \mathrm{Ne}, \mathrm{Ar}, \mathrm{Kr}, \mathrm{N}_{2}, \mathrm{O}_{2}, \mathrm{CH}_{4}, \mathrm{CO}_{2}$ and $\mathrm{H}_{2}$ with a time resolution of a few seconds in gases or better than $15 \mathrm{~min}$ in liquids.

Here, we present on how the miniRUEDI instrument can be applied

- $\quad$ in full-scale experiments to assess the gas evolution in caverns designed for radioactive waste disposal [5] and

- $\quad$ in experiments to analyze the dynamics of pore fluids during rock fracking tests [6].

Based on these examples, we discuss how noble gases can provide insights on the dynamics of reactive gas species in the subsurface.

Other authors: Environmental Isotope Group and Ruedi Ruessel, Dept. of Water Resources and Drinking Water, Swiss Federal Institute of Aquatic Science and Technology (Eawag), 8600 Dübendorf, Switzerland

[1] Grundl T. et al. (2013) Earth Planet. Sci. Lett. 369-370, 78-85.

[2] Brennwald M. S. et al. (2016) Environ. Sci. Technol. 50, 13455-13463.

[3] Chatton E. et al. (2017) Environ. Sci. Technol. 51, 846854.

[4] Gasometrix GmbH, www.gasometrix.com. 